\title{
Possible association of ghrelin/obestatin balance with cardiometabolic risk in obese subjects with Helicobacter pylori
}

\author{
Azza Saad Ibrahim ${ }^{1}$, Mona Mohamed Eldeeb ${ }^{2}$, Ola Ahmed Salama ${ }^{3}$, \\ Mona Mohamed Rash AD ${ }^{4}$, Khaled Mohamed OKasha ${ }^{4}$
}

\begin{abstract}
${ }^{1}$ Medical Research Institute, Alexandria University, Alexandria, Egypt; ${ }^{2}$ Department of Chemical Pathology, Medical Research Institute, Alexandria University, Alexandria, Egypt; ${ }^{3}$ Department of Physiology, Medical Research Institute, Alexandria University, Alexandria, Egypt; ${ }^{4}$ Department of Applied Medical Chemistry, Medical Research Institute, Alexandria University, Alexandria, Egypt

E-mail:azzasaad_mri@yahoo.com
\end{abstract}

\begin{abstract}
Objectives. Helicobacter pylori (H. pylori) is a common gastric infection associated with extragastric conditions. The association between $\mathrm{H}$. pylori infection and obesity is unclear. H. pylori may affect gut hormones involved in food intake and energy expenditure. The aim of this study is to evaluate ghrelin/obestatin balance and leptin in obese subjects with $\mathrm{H}$. pylori infection.

Methods. Sixty healthy volunteers were divided into: obese and non-obese groups. Each group was divided into H. Pylori positive or H. pylori negative. Anthropometric parameters, H. pylori status, serum glucose, insulin level, and lipid profile were estimated with calculation of Homeostasis Model Assessment Insulin Resistance (HOMA-IR). Serum levels of ghrelin, obestatin, and leptin were evaluated.
\end{abstract}

Results. Significant increase was found in serum glucose, insulin and HOMA-IR ratio in obese subjects with positive $\mathrm{H}$. pylori as compared to other groups. H. pylori positive obese subjects showed significantly increased ghrelin, ghrelin/obestatin balance, and leptin with a significant decrease in obestatin as compared to negative subjects. Ghrelin/obestatin ratio positively correlated with weight, body mass index, waist, glucose, insulin, HOMA-IR, leptin, cholesterol, triglycerides, low density cholesterol and also with $\mathrm{H}$. pylori antigen in the same group.

Conclusions. It can be concluded that ghrelin, obestatin, and leptin are affected by presence of H. pylori seropositivity in obese subjects. The higher ghrelin levels and ghrelin/obestatin ratio with lowered obestatin could be considered as a gastro-protective effect against inflammation induced by $\mathrm{H}$. pylori.

Key words: obesity, H. pylori, ghrelin, obestatin, leptin

Obesity is one of the major health problems. According to the WHO, its prevalence has been rising rapidly in recent years (Zhang et al. 2015). Studies have suggested that some non-communicable infections as Helicobacter pylori (H. pylori) may be related to obesity, a condition termed as "infectobesity" (Du et al. 2013). H. pylori is a common infection having a role in the development of different gastric lesions (Carabotti et al. 2014). Several studies have stated that infection of $\mathrm{H}$. pylori is associated with various extragastric conditions, such as diabetes mellitus (DM), dyslipidemia, and cardiovascular disease (Quatrini et al. 2001; Choi et al. 2016).

The association between $\mathrm{H}$. pylori and obesity revealed contradicting results; "A meta-analysis including 10,000 subjects detected a higher body mass index among $\mathrm{H}$. pylori-positive subjects compared with H. pylori-negative subjects". There was no signifi-

Corresponding author: Azza Saad Ibrahim, M.D., Medical Research Institute, Alexandria University, Alexandria, Egypt; e-mail: azzasaad_mri@yahoo.com. 
cant difference regarding other coronary risk factors found, except the high-density lipoprotein, which is lower in the infected subjects (Boltin and Niv 2012). However, "a study showed a significant elevation in the body mass after eradication of $\mathrm{H}$. pylori in a European population, a phenomenon previously observed in Asian populations" (Fujiwara et al. 2002).

A large amount of epidemiologic and clinical data regarding associations with non-gastric systemic diseases and $\mathrm{H}$. pylori infection have been reported, including cardiovascular disease and its risk factors (Satoh et al. 2010). However, the results of several other researchers failed to confirm the association (Sotiropoulos et al. 2006).

A defect that occurs in the obesity is the development of resistance to the action of key metabolic hormones such as leptin and ghrelin (Cui et al. 2017). In addition, $H$. pylori has been shown to influence appetite and weight regulating hormones as ghrelin, obestatin, and leptin. Ghrelin, a 28-amino acid, is a gut-brain peptide that regulates food intake and has a strong growth hormone releasing activity. It stimulates the hypothalamic appetite center through stimulation of neuropeptides and directly regulates gastrointestinal function and appetite (Khosravi et al. 2016).

The chronic persistent damage to gastric mucosa, which occurs in $\mathrm{H}$. pylori infection may affect ghrelin production as it is mostly synthesized and secreted by gastric endocrine cells leading to alterations in food intake and body weight (Chen et al. 2009). In adults, there are contradicting results regarding the relation between $\mathrm{H}$. pylori infection and ghrelin. Studies have shown that $H$. pylori infection decreased ghrelin secretion, however, studies found that $\mathrm{H}$. pylori infection had no influence on plasma ghrelin levels (Osawa et al. 2005; Cindoruk et al. 2007). Preproghrelin is a common precursor of obestatin and ghrelin. However, obestatin shows opposite effects to ghrelin. Obestatin antagonizes growth hormone secretion and reduces food intake. Its discovery in 2005 added to the complexity of understanding ghrelin (Hassouna et al. 2010). It is probable that ghrelin, obestatin, and leptin work together to regulate homeostasis and body weight.

Therefore, this study was aimed to investigate the ghrelin/obestatin balance and leptin in obese subjects to find out whether it is related to cardiometabolic risk in obese subjects with $\mathrm{H}$. pylori infection.

\section{Subjects and Methods}

Subjects. This study was carried on sixty healthy adult male subjects aged from 30 to 50 years. Subjects were divided into two groups according to body mass index (BMI), waist circumference (WC) and waisthip ratio (WHR). Group 1: 30 non-obese subjects $\left(\mathrm{BMI}<30 \mathrm{~kg} / \mathrm{m}^{2}, \mathrm{WC} \leq 94 \mathrm{~cm}\right.$ and $\left.\mathrm{WHR} \leq 0.8\right)$. Group 2: 30 obese patients $\left(B M I \geq 30 \mathrm{~kg} / \mathrm{m}^{2}, W C>94 \mathrm{~cm}\right.$, WHR >1). Both groups were classified as H. pylori positive $(+)$ or $\mathrm{H}$. pylori negative $(-)$ according to presence or absence of $H$. pylori antigen in the stool. Subjects with serious infections, heart, lung, kidney or other major organ disorders, use of drugs that may affect $\mathrm{H}$. pylori results (antibiotics, H2 blockers, proton pump inhibitors, bismuth preparations and use of corticosteroids) were excluded from the study. After approval by Ethical committee, written consents were taken from subjects attending Medical Research Institute, Alexandria University.

Anthropometrical measurements. The WC and WHR were measured for each subject, BMI was calculated as body weight $(\mathrm{kg}) /$ height $\left(\mathrm{m}^{2}\right)$ (Garrow and Webster 1985).

H. pylori antigen was detected in the stool specimens by enzyme linked immunosorbant assay (ELISA).

Biochemical parameters. Seven $\mathrm{ml}$ fasting venous blood samples (10-12 h) were obtained from each subject at 7.00-8.00 a.m. Blood samples were allowed to clot for $30 \mathrm{~min}$ before centrifugation, centrifuged at $3000 \mathrm{rpm}$ for $10 \mathrm{~min}$ to isolate sera. The serum was divided into 4 aliquots. One aliquot was used immediately for colorimetric determination fasting serum glucose, lipid profile [total serum cholesterol, triglycerides (TG), high density cholesterol (HDL-C), and low-density cholesterol (LDL-C)] (Burtis et al. 2006).

Second serum aliquot was used for Immunoradiometric assay (IRMA) of fasting serum insulin (Chevenne et al. 2001) were the ${ }^{125}$ I-labeled signalantibody (tracer) binds to an epitope of the insulin molecule, which is spatially different from that recognized by the biotin capture-antibody. The two antibodies react simultaneously with the antigen present in standards or samples leading to formation of a capture antibody-antigen-signal antibody complex "sandwich". The immuno-complex is immobilized to the reactive surface of streptavidin-coated test tubes within 2-h incubation. The reaction mixture is then discarded, test tubes washed and radioactivity is measured in a gamma counter were the concentration of antigen is directly proportional to the radioactivity measured in test tubes (Matthews et al. 1985).

Another serum aliquot was used to estimate Homeostasis Model Assessment Insulin Resistance (HOMA-IR) according to the formula HOMA-IR = fasting insulin $(\mathrm{IU} / \mathrm{ml}) \times$ fasting glucose $(\mathrm{mmol}) / 22.5$ (Wallace et al. 2004). 
To evaluate H. pyroli status, the fourth serum aliquot was used to determine IgG antibodies against $\mathrm{H}$. pylori by ELISA (Goodwin et al. 1997).

The remaining serum aliquots were stored at $-70^{\circ} \mathrm{C}$ until used for estimating the levels of total ghrelin, obestatin and leptin using Enzyme Immunoassay (EIA) Kit, an in vitro quantitative assay based on the competitive enzyme immunoassay principle purchased from the RayBio ${ }^{\circ}$ company (Yildiz et al. 2004; Hassouna et al. 2010). Intra-assay and inter-assay were $\mathrm{CV}<10 \%$ and $\mathrm{CV}<15 \%$, respectively, with no cross reactivity. Following the manufactures instruction results were deduced from appropriately plotted standard curve.

Statistical analysis. Statistical analysis was performed using SPSS 20 software package. Quantitative data were represented as mean \pm standard error. The distributions of quantitative variables were tested for normality using Kolmogrov-Smirnov test and Shapiro-Wilk test. D'Agstino test was used if there was a conflict between the two previous tests. The data were normally distributed and parametric tests were used. The student $\mathrm{t}$-test was used for studying differences between obese group and non-obese group and the comparison between groups was performed using ANOVA test. The parametric Pearson test was used for correlating studied serum parameters concentrations ghrelin/obestatin ratio. The value $\mathrm{p}<0.05$ was considered statistically significant.

\section{Results}

Results of anthropometric measurements and biochemical findings were compared in the four studied groups using ANOVA test (Table 1). Significant changes were found between the four groups in all parameters except WHR, serum TG, HDL-C and LDL-C. By comparing +ve and -ve cases, no significant differences in weight, BMI, WC, fasting glucose, serum TG, HDL-C and LDL-C were detected.

Table 1

Anthropometric measurements, serum fasting glucose $(\mathrm{mg} / \mathrm{dl})$, fasting insulin $(\mu \mathrm{IU} / \mathrm{ml})$, homeostatic model assessment-insulin resistance (HOMA-IR) and the lipid profile in obese and non-obese with and without H. Pylori.

\begin{tabular}{|c|c|c|c|c|c|c|c|c|}
\hline \multirow{2}{*}{ Parameter } & \multicolumn{2}{|c|}{$\begin{array}{c}\text { Obese } \\
(n=30)\end{array}$} & \multirow[t]{2}{*}{$\begin{array}{c}\text { OR } \\
(95 \% \text { LL-UL) }\end{array}$} & \multicolumn{2}{|c|}{$\begin{array}{c}\text { Non obese } \\
(\mathrm{n}=30)\end{array}$} & \multirow[t]{2}{*}{$\begin{array}{c}\text { OR } \\
(95 \% \text { LL-UL) }\end{array}$} & \multirow[t]{2}{*}{ F } & \multirow[t]{2}{*}{ p-value } \\
\hline & $-v e(n=13)$ & $+v e(n=17)$ & & $-v e(n=15)$ & $+v e(n=15)$ & & & \\
\hline $\begin{array}{l}\text { Weight } \\
(\mathrm{kg})\end{array}$ & $95.69 \pm 9.64$ & $95.71 \pm 18.04$ & $1(1-1.1)$ & $72.33 \pm 9.17^{\mathrm{a}}$ & $72.40 \pm 13.17^{\mathrm{b}}$ & $1(0.9-1.1)$ & $15.353^{*}$ & $<0.001^{*}$ \\
\hline $\begin{array}{l}\text { Height } \\
\text { (m) }\end{array}$ & $1.69 \pm 0.10$ & $1.65 \pm 0.10$ & $0.2(0-31.4)$ & $1.74 \pm 0.11$ & $1.76 \pm 0.14$ & $2.6(0-937.3)$ & $2.895^{*}$ & $0.043^{*}$ \\
\hline $\begin{array}{l}\mathrm{BMI} \\
\left(\mathrm{kg} / \mathrm{m}^{2}\right)\end{array}$ & $33.69 \pm 3.63$ & $35.32 \pm 4.27$ & $1.1(0.9-1.4)$ & $23.77 \pm 1.12^{\mathrm{a}}$ & $23.36 \pm 1.28^{\mathrm{b}}$ & $0.7(0.4-1.4)$ & $70.390^{*}$ & $<0.001^{*}$ \\
\hline $\begin{array}{l}\text { Waist } \\
(\mathrm{cm})\end{array}$ & $108.08 \pm 6.61$ & $106.0 \pm 11.03$ & $1(0.9-1.1)$ & $72.93 \pm 8.81^{\mathrm{a}}$ & $74.0 \pm 9.66^{\mathrm{b}}$ & $1(0.9-1.1)$ & $64.397^{*}$ & $<0.001^{*}$ \\
\hline $\begin{array}{l}\text { Waist/Hip } \\
\text { Ratio }\end{array}$ & $0.77 \pm 0.05$ & $0.75 \pm 0.06$ & $0(0-432.2)$ & $0.75 \pm 0.08$ & $0.75 \pm 0.09$ & $0.5(0-1940.6)$ & 0.273 & 0.845 \\
\hline $\begin{array}{l}\text { Fasting glucose } \\
(\mathrm{mg} / \mathrm{dl})\end{array}$ & $91.38 \pm 9.81$ & $105.12 \pm 19.92$ & $1.1(1-1.1)$ & $78.60 \pm 11.65$ & $83.73 \pm 7.94^{\mathrm{b}}$ & $1.1(1-1.1)$ & $11.698^{*}$ & $<0.001^{*}$ \\
\hline $\begin{array}{l}\text { Fasting insulin } \\
(\mu \mathrm{IU} / \mathrm{ml})\end{array}$ & $15.05 \pm 3.16$ & $25.85 \pm 5.62^{\mathrm{a}}$ & $1.7(1.1-2.6)$ & $8.15 \pm 1.76^{\mathrm{a}}$ & $10.26 \pm 3.26^{\mathrm{b}}$ & $1.5(1-2.3)$ & $69.475^{*}$ & $<0.001^{*}$ \\
\hline HOMA-IR & $1.94 \pm 0.38$ & $3.35 \pm 0.73^{\mathrm{a}}$ & $\begin{array}{c}190.1 \\
(2.3-15446)\end{array}$ & $1.03 \pm 0.25^{\mathrm{a}}$ & $1.31 \pm 0.38^{\mathrm{b}}$ & $27.9(1-787)$ & $73.945^{*}$ & $<0.001^{*}$ \\
\hline $\begin{array}{l}\text { Cholesterol } \\
(\mathrm{mg} / \mathrm{dl})\end{array}$ & $183.62 \pm 32.53$ & $180.53 \pm 30.0$ & $1(1-1)$ & $133.20 \pm 24.08^{\mathrm{a}}$ & $184.20 \pm 28.18^{c}$ & $1.1(1-1.2)$ & $11.131^{*}$ & $<0.001^{*}$ \\
\hline $\begin{array}{l}\text { Triglycerides } \\
\text { (mg/dl) }\end{array}$ & $149.46 \pm 32.19$ & $142.88 \pm 41.08$ & $1(1-1)$ & $122.27 \pm 31.46$ & $132.13 \pm 30.51$ & $1(1-1)$ & 1.745 & 0.168 \\
\hline $\begin{array}{l}\text { HDL-C } \\
(\mathrm{mg} / \mathrm{dl})\end{array}$ & $39.38 \pm 4.63$ & $39.82 \pm 10.06$ & $1(0.9-1.1)$ & $36.60 \pm 9.55$ & $34.80 \pm 3.91$ & $1(0.9-1.1)$ & 1.429 & 0.244 \\
\hline $\begin{array}{l}\text { LDL-C } \\
(\mathrm{mg} / \mathrm{dl})\end{array}$ & $114.46 \pm 27.29$ & $111.94 \pm 24.45$ & $1(1-1)$ & $102.60 \pm 29.50$ & $124.87 \pm 23.82$ & $1(1-1.1)$ & 1.712 & 0.175 \\
\hline
\end{tabular}

Quantitative parameters are expressed as mean \pm SD. F - F test (ANOVA); $\mathrm{a}$ - significant vs. -ve obese group; $\mathrm{b}$ - significant vs. +ve obese group; c - significant vs. -ve non-obese group. Abbreviations: BMI - body mass index; HDL-C - high-density cholesterol; LDLC - low-density cholesterol. 
Values of biochemical parameters were within normal changes in all groups, but it was noticed that obese subjects with +ve H. pylori had higher glucose, HOMA-IR and serum insulin levels when compared with other groups. As regards cholesterol level, significant differences were obtained between -ve and +ve cases in non-obese subjects only. F values and $\mathrm{p}$ are shown in Table 1.

Results of serum ghrelin and obestatin levels showed significant differences between -ve and +ve cases either obese or non-obese subjects $(\mathrm{p}<0.001)$. Using ANOVA, a significant difference was noticed between groups $\left(\mathrm{F}=323.505, \mathrm{p}<0.001^{*}\right)$ and $(\mathrm{F}=69.071$, $\left.\mathrm{p}<0.001^{\star}\right)$. Obese $+\mathrm{ve}$ subjects demonstrated the highest ghrelin and lowest obestatin levels when compared to other groups (Figures 1 and 2). Leptin values revealed that obese +ve subjects showed significant higher levels as compared to -ve cases. While no significant change was obtained in non-obese subjects using ANOVA, a significant difference was noticed between groups $\left(\mathrm{F}=530.665, \mathrm{p}<0.001^{\star}\right)$ and obese + ve

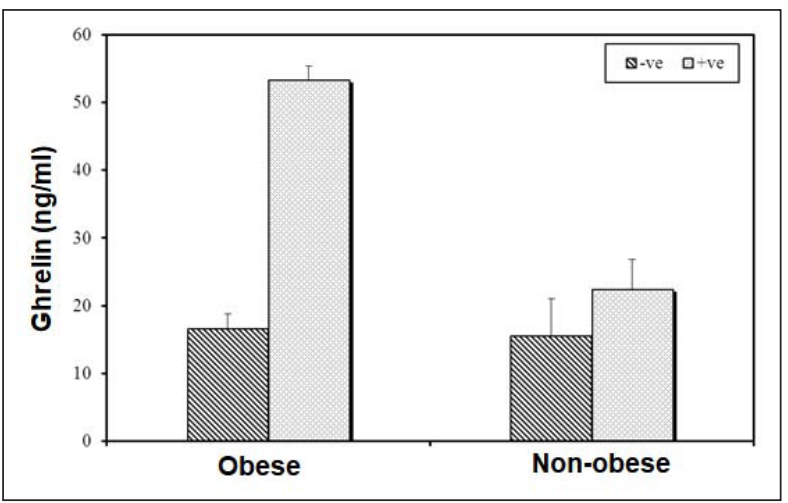

Figure 1. Ghrelin level $(\mathrm{ng} / \mathrm{ml})$ in obese and non-obese subjects with and without $\mathrm{H}$. pylori.

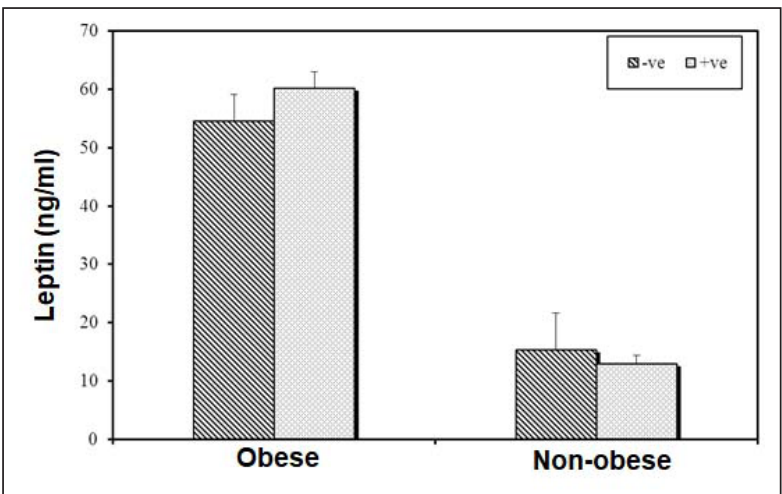

Figure 3. Leptin level $(\mathrm{ng} / \mathrm{ml})$ in obese and non-obese subjects with and without $\mathrm{H}$. pylori. subjects showed higher levels as compared to other groups (Figure 3).

Figure 4 illustrates findings of ghrelin/obestatin ratio. A significant difference obtained between -ve and +ve cases either obese or non-obese, also using ANOVA, a significant difference was noticed between groups $\left(\mathrm{F}=349.917, \mathrm{p}<0.001^{*}\right)$. In addition, $\mathrm{H}$. pylori +ve subjects have significant higher ghrelin/obestatin ratio levels than -ve subjects in both obese and nonobese. Obese +ve subjects demonstrated the highest ghrelin/obestatin ratio levels when compared to other groups.

Table 2 shows correlations between ghrelin/ obestatin ratio and the other studied parameters.

\section{Discussion}

The involvement of H. pylori in the pathophysiology of obesity is still debated. The infection may be protective against obesity, because of the gastritisinduced changes in some stomach hormones. How-

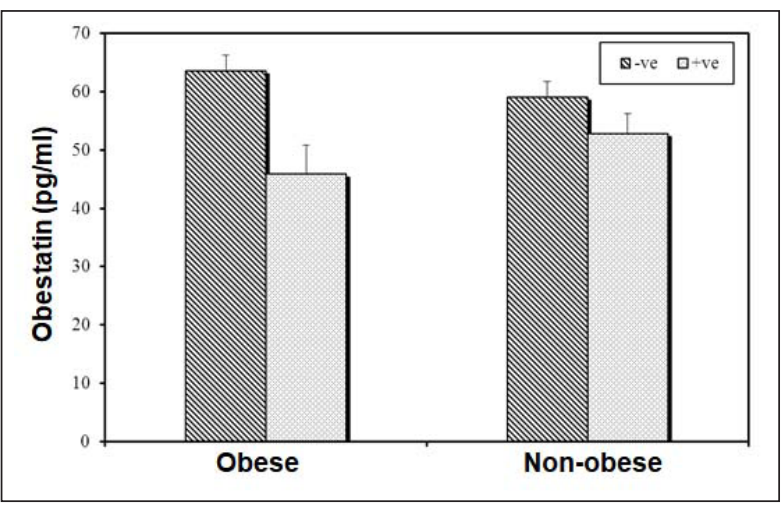

Figure 2. Obestatin level $(\mathrm{pg} / \mathrm{ml})$ in obese and non-obese subjects with and without $\mathrm{H}$. pylori.

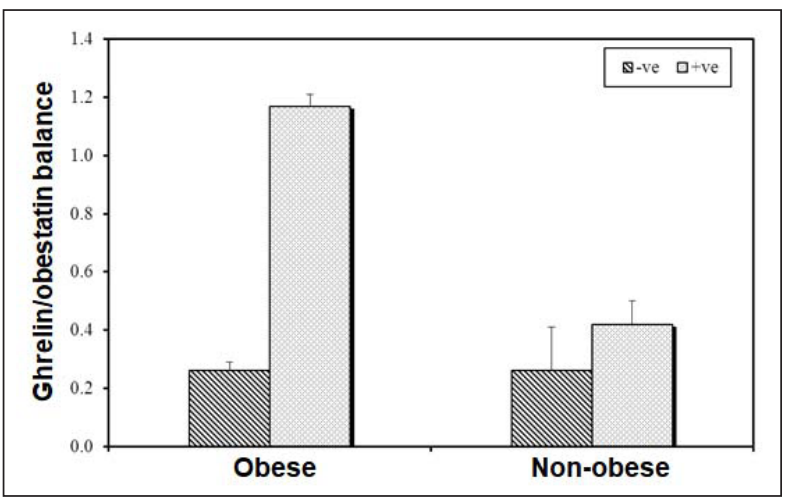

Figure 4. Ghrelin/obesatin ratio in obese and non-obese subjects with and without $\mathrm{H}$. pylori. 
Table 2

Correlation between ghrelin/obestatin ratio with different parameters in each group.

\begin{tabular}{|c|c|c|c|c|c|c|c|c|}
\hline \multirow{3}{*}{ Parameter } & \multicolumn{4}{|c|}{ Obese } & \multicolumn{4}{|c|}{ Non-obese } \\
\hline & \multicolumn{2}{|c|}{-ve } & \multicolumn{2}{|c|}{$+\mathrm{ve}$} & \multicolumn{2}{|c|}{-ve } & \multicolumn{2}{|c|}{ +ve } \\
\hline & $\mathbf{r}$ & p-value & $\mathbf{r}$ & p-value & $\mathbf{r}$ & p-value & $\mathbf{r}$ & p-value \\
\hline Age (years) & 0.094 & 0.761 & 0.169 & 0.518 & 0.250 & 0.369 & -0.094 & 0.739 \\
\hline Weight (kg) & $-0.671^{*}$ & 0.012 & $0.632^{*}$ & 0.007 & -0.313 & 0.256 & -0.090 & 0.749 \\
\hline Height (m) & 0.276 & 0.360 & -0.004 & 0.989 & -0.367 & 0.178 & -0.135 & 0.632 \\
\hline BMI $\left(\mathrm{kg} / \mathrm{m}^{2}\right)$ & $-0.808^{*}$ & 0.001 & $0.639^{*}$ & 0.006 & 0.171 & 0.541 & $0.775^{*}$ & 0.001 \\
\hline Waist (cm) & 0.197 & 0.519 & $0.633^{*}$ & 0.006 & 0.011 & 0.970 & -0.342 & 0.212 \\
\hline Hip (cm) & 0.057 & 0.852 & -0.278 & 0.280 & -0.069 & 0.808 & -0.304 & 0.271 \\
\hline Waist/Hip ratio & 0.110 & 0.721 & -0.066 & 0.800 & 0.089 & 0.753 & -0.237 & 0.395 \\
\hline Fasting glucose & $-0.807^{*}$ & 0.001 & $0.649^{*}$ & 0.005 & 0.021 & 0.940 & $0.609^{*}$ & 0.016 \\
\hline Fasting insulin & $-0.762^{*}$ & 0.002 & $0.562^{*}$ & 0.019 & -0.279 & 0.314 & $0.582^{*}$ & 0.023 \\
\hline HOMA-IR & $-0.710^{*}$ & 0.007 & $0.638^{*}$ & 0.006 & -0.219 & 0.434 & $0.774^{*}$ & 0.001 \\
\hline Cholesterol & $-0.732^{*}$ & 0.004 & $0.550^{*}$ & 0.022 & 0.300 & 0.277 & $0.710^{*}$ & 0.003 \\
\hline Triglycerides & $-0.828^{*}$ & $<0.001$ & $0.510^{*}$ & 0.036 & 0.105 & 0.709 & -0.161 & 0.566 \\
\hline HDL-C & 0.149 & 0.628 & 0.203 & 0.434 & 0.148 & 0.600 & 0.052 & 0.854 \\
\hline LDL-C & $-0.719^{*}$ & 0.006 & $0.683^{*}$ & 0.003 & 0.323 & 0.240 & -0.151 & 0.591 \\
\hline Leptin (ng/ml) & -0.134 & 0.663 & 0.007 & 0.978 & -0.234 & 0.402 & - & - \\
\hline H. Pylori Ag "stool" & $-0.741^{*}$ & 0.004 & $0.551^{*}$ & 0.022 & -0.059 & 0.836 & $0.600^{*}$ & 0.018 \\
\hline
\end{tabular}

Abbreviations: BMI - body mass index; HOMA-IR - homeostatic model assessment-insulin resistance; HDL-C - high-density cholesterol; LDL-C - low-density cholesterol; Ag - antigen

ever, other studies have failed to show an association between $\mathrm{H}$. pylori infection and reduced body mass index (Carabotti et al. 2014).

The present study demonstrated the association between ghrelin/obestatin balance and $\mathrm{H}$. pylori in obese subjects. $\mathrm{H}$. pylori is the major pathogen of the gastrointestinal tract. It has been suggested that it may influence production of some peptides in the stomach, which can affect appetite. The chronic persistent damage to the gastric mucosa, which occurs in $\mathrm{H}$. pylori infection, may affect ghrelin production and lead to changes in food intake and body weight (Deng et al. 2012).

H. pylori is known to play a crucial role in gastritis, gastroduodenal ulcer disease, and in gastric carcinoma. Moreover, chronic corpus gastritis and mucosal atrophy reduce gastric acid secretions. Gastrin and somatostatin are regulatory hormones that affect gastric acid secretion in the gastric mucosa. H. pylori infection has been shown to reduce plasma somatostatin and increase plasma gastrin concentrations. It has been demonstrated that central ghrelin administration inhibits gastric acid secretion, but that peripheral ghrelin administration does not modify gastric acid secretion in rats. Thus, the possibility exists that ghrelin and $\mathrm{H}$. pylori infection may be associated (Choe et al. 2007).

It has been identified a proinflammatory signaling mechanism between gastric and adipose tissues which is coordinated by $\mathrm{H}$. pylori infection and obesity (Ericksen et al. 2014). Over time, this proinflammatory milieu up-regulated local and systemic proinflammatory factors and accelerated the process of gastric inflammation and even carcinogenesis. Obese inflamed adipose tissue, compared with lean adipose tissue, appears to have the unique ability to amplify $\mathrm{H}$. pylori-associated inflammation via a complex signaling loop.

It was reported that $\mathrm{H}$. pylori infection causes the release of many pro inflammatory cytokines, such as interleukin (IL)-1, IL-6 and IL-8, and influences decreases in ghrelin production (Chuang et al. 2009). The relationship between $\mathrm{H}$. pylori infection and ghrelin showed contradictory reports.

It has been reported that the plasma ghrelin concentrations of $\mathrm{H}$. pylori-positive and -negative groups did not differ significantly, indicating that $\mathrm{H}$. pylori infection has no effect on stomach ghrelin levels and that eradication therapy does not influence plasma or tissue ghrelin levels (Gokcel et al. 2003). On the other 
hand, other studies have shown that plasma ghrelin increases significantly after $\mathrm{H}$. pylori eradication and that this leads to an increased appetite and weight gain and contributes to increasing obesity and gastroesophageal reflux disease (Nwokolo et al. 2003).

In the present study, $\mathrm{H}$. pylori positive subjects showed significant increased ghrelin and ghrelin/obestatin balance and a significant decreased obestatin as compared to negative subjects. The most significant changes were observed in obese subjects. This is clearly evident, as a significant positive correlation was found between ghrelin/obestatin balance and weight, BMI, WC and H. pylori antigen. Similar to the findings of the present work, it has been reported that $\mathrm{H}$. pylori-infected mucosa had more ghrelin than non-infected mucosa, regardless of gender and stomach topography (Stec-Michalska et al. 2009). Moreover, other researchers have found decreased ghrelin with increased obestatin in H. pylori-eradicated subjects (Ulasoglu et al. 2013).

It is known that $\mathrm{H}$. pylori infection may lead to the early stage of inflammatory changes described as non-atrophic gastritis, which causes activation of protective mechanisms in the mucosa and results in an increase in gastric ghrelin expression. This increase was more prominent in the gastric mucosa of both male and female patients infected with $\mathrm{H}$. pylori (Stec-Michalska et al. 2009). The authors have explained that ghrelin levels in the gastric mucosa significantly decreased with more advanced histopathological changes, especially after the atrophic gastritis stage. It has been suggested that the level of this hormone can be considered as one of the markers of gastric mucosal change progression and, at the same time, it can be one of the indications for gastroscopy (Stec-Michalska et al. 2009). It has been reported that plasma acylated ghrelin levels were higher in patients with chronic atrophic gastritis than in healthy subjects (Campana et al. 2007). This opposite tendency compared to total plasma ghrelin concentration may result from the compensatory increase in plasma active ghrelin concentration in response to gastric atrophy. This hypothesis was supported by showing that a significant decrease in gastric $\mathrm{pH}$ was found after injection of exogenous ghrelin (Osawa 2008). Gastric atrophy causes an increase in gastric $\mathrm{pH}$, leading to an increase in serum gastrin levels. Both the increase in acylated ghrelin and gastrin could represent a compensatory mechanism to stimulate gastric acid production. Therefore, the discrepancies between our results (higher ghrelin level in $\mathrm{H}$ pylori positive patients) and the previously published data could be explained due to different stages of gastric mucosa inflammatory changes (gastritis, peptic ulcer). It is well known that the ghrelin gene also encodes the obestatin peptide. It was initially reported that obestatin functioned against ghrelin; for example, obestatin reduced refeeding, whereas ghrelin stimulated food intake and gastric transit (Zhang et al. 2005).

It is possible that ghrelin and obestatin work together to regulate homeostasis and body weight. Similar to our findings, decreased obestatin levels obtained in obese positive $\mathrm{H}$. pylori subjects, other studies in humans have shown that plasma obestatin levels are significantly lower in obese subjects, as compared to lean controls, indicating a role for obestatin in longterm body weight regulation (Huda et al. 2008).

Lee et al. (2010) have reported that the stomach is considered an important organ for obestatin secretion, because obestatin can be purified from the stomach and tends to be lower in gastrectomy patients. However, H. pylori infection or its treatment can affect gastric obestatin production (Huda et al. 2008). Significant higher leptin levels were also found in the present work in obese subjects with positive $\mathrm{H}$. pylori as compared to other groups. In addition, the increased leptin levels were found to correlate positively with ghrelin/obestatin balance.

Serum leptin, which is primarily synthesized by adipose tissue, regulates food intake and body weight homeostasis. Leptin is now known to be synthesized in the stomach as well, and this source may also be involved in the regulation of food intake and satiety. Gastric inflammation induced by $\mathrm{H}$. pylori alters leptin secretion in the stomach. The change in gastric leptin level resulting from $\mathrm{H}$. pylori-induced inflammation may influence food intake and BMI (Cho et al. 2005). Eradication of H. pylori is associated with decreased gastric leptin levels and subsequent weight changes, although serum leptin levels did not change (Azuma et al. 2001).

Moreover, findings of the present study demonstrated higher serum glucose, insulin levels with increased HOMA-IR index and lipid profile in positive $\mathrm{H}$. pylori obese subjects. These findings suggest that H. pylori infection could be considered as a risk factor for insulin resistance. These alterations may be explained by the low-grade inflammation which may influence fat turnover and support insulin resistance with consequent alterations of glucose and lipid metabolism. A study of Aydemir et al. (2005) showed higher HOMA-IR scores in $\mathrm{H}$. pyroli positive (HP $+\mathrm{ve})$ individuals.

As insulin resistance can develop in the presence of inflammation or as a result of alterations in coun- 
ter regulatory hormones that affect insulin, H. pylori may thus promote insulin resistance by inducing chronic inflammation and affecting insulin-regulating gastrointestinal hormones (Aydemir et al. 2005).

It is commonly believed that the chronic inflammation induced by $\mathrm{H}$. pylori infection is strongly associated to the pathogenesis of diabetes, which is linked to general activation of the innate immune system with a chronic, cytokine-mediated state of low-grade inflammation (Fernandez-Real and Pickup 2008). It has been also reported that $H$. pylori infection may influence the pathophysiology of insulin resistance through impairment of ghrelin and leptin with elevation of insulin. These are associated with impaired energy homeostasis, lipid metabolism, and insulin sensitivity (Osawa et al. 2005).

The present study showed the association between ghrelin/obestatin balance and increased glucose, insulin and HOMA-IR values in obese subjects with positive $\mathrm{H}$. pylori thus confirming its role in promoting the insulin resistance.

It is well known that inflammation of adipose tissue in obese subjects is considered a key factor in the pathogenesis of insulin resistance and $\beta$-cell potential auto inflammation impairs insulin secretion. $\mathrm{H}$. pyroli-induced gastritis can affect the secretion of gastric related hormones such as leptin and ghrelin as well as gastrin and somatostatin, which may influence a predisposition to diabetes (Jeffery et al. 2011).

The obtained lipid profile in the present study in all groups were non-pathological. However, an association of ghrelin/obestatin balance with the lipid profile were noticed in obese subjects with positive H. pylori. While H. pylori does not enter circulation, extragastric manifestations are probably mediated by the cytokines and acute phase proteins produced by the inflamed mucosa. An increase of total low-den- sity lipoprotein cholesterol levels in infected people could create an atherogenic lipid profile that promote atherosclerosis (Buzas et al. 2014). The association of H. pylori infection with lipid profile changes was observed earlier in 1996 in Finnish subjects, their serum cholesterol and TG levels were significantly higher in H. pylori-infected male persons after adjustment of age and BMI (Buzas et al. 2014). More recently, Kim et al. (2016) have found that subjects with $\mathrm{H}$. pylori infection had higher total cholesterol and LDL-C, as well as lower HDL-C. They explained that alterations of lipid profile may be mediated by inflammatory cytokines such as IL-1, IL-6, or tumor necrosis factor- $\alpha$ (TNF- $\alpha$ ) through a chronic inflammatory condition induce by $\mathrm{H}$. pylori.

A study of Gen et al. (2010) has shown beneficial effects of $\mathrm{H}$. pylori eradication on insulin resistance, atherogenic lipid abnormalities and low-grade inflammation and suggested that $\mathrm{H}$. pylori eradication may prevent coronary artery disease and metabolic syndrome.

In conclusion, based on the results obtained, the higher ghrelin levels and ghrelin/obestatin ratio with lowered obestatin could be considered as a gastroprotective effect against inflammation induced by $\mathrm{H}$. pylori. Ghrelin and obestatin hormones, and ghrelin/obestatin ratio could be considered as markers for gastric mucosal progression in infected subjects and may also reflect the effectiveness of treatment. However, the discrepancies between our findings and other reported data indicate that further research is needed.

Findings indicate that this hormonal imbalance associated with $\mathrm{H}$. pylori may predispose to some metabolic alterations, such as insulin resistance. Early eradication of $\mathrm{H}$. pylori is recommended to control the associated metabolic consequences.

\section{References}

Aydemir S, Bayraktaroglu T, Sert M, Sokmen C, Atmaca H, Mungan G, Gun BD, Borazan A, Ustundag Y. The effect of Helicobacter pylori on insulin resistance. Dig Dis Sci 50, 2090-2093, 2005.

Azuma T, Suto H, Ito Y, Ohtani M, Dojo M, Kuriyama M, Kato T. Gastric leptin and Helicobacter pylori infection. Gut 49, 324-329, 2001.

Boltin D, Niv Y. Ghrelin, Helicobacter pylori and body mass: is there an association? Isr Med Assoc J 14, 130-132, 2012.

Burtis CA, Ashwood ER, Bruns DE. Tietz Textbook of Clinical Chemistry and Molecular Diagnostics (4 ${ }^{\text {th }}$ Ed.). Elsevier, Saunders, St. Louis, 2006.

Buzas GM. Metabolic consequences of Helicobacter pylori infection and eradication. World J Gastroenterol 20, 5226-5234, 2014.

Campana D, Nori F, Pagotto U, De Iasio R, Morselli-Labate AM, Pasquali R, Corinaldesi R, Tomassetti P. Plasma acylated ghrelin levels are higher in patients with chronic atrophic gastritis. Clin Endocrinol (Oxf), 67, 761766, 2007. 
Carabotti M, D’Ercole C, Iossa A, Corazziari E, Silecchia G, Severi C. Helicobacter pylori infection in obesity and its clinical outcome after bariatric surgery. World J Gastroenterol 20, 647-653, 2014.

Chen CY, Asakawa A, Fujimiya M, Lee SD, Inui A. Ghrelin gene products and the regulation of food intake and gut motility. Pharmacol Rev 61, 430-481, 2009.

Chevenne D, Letailleur A, Trivin F, Porquet D. Effect of hemolysis on the concentration of insulin in serum determined by RIA and IRMA. Clin Chem 44, 354-356, 2001.

Cho I, Blaser MJ, François F, Mathew JP, Ye XY, Goldberg JD, Bini EJ. Helicobacter pylori and overweight status in the United States: data from the third national health and nutrition examination survey. Am J Epidemiol $162,579-84,2005$.

Choe YH, Lee JH, Lee HJ, Paik KH, Jin DK, Song SY, Lee JH. Ghrelin levels in gastric mucosa before and after eradication of H. pylori. Gut and Liver 1, 132-137, 2007.

Choi J, Ko K, Lim J, Cheon E, Lee G, Yoon J. The association between Helicobacter pylori infection and body weight among children. Pediatr Gastroenterol Hepatol Nutr 19, 110-115, 2016.

Chuang CH, Sheu BS, Yang HB, Lee SC, Kao AW, Cheng HC, Chang WL, Yao WJ. Gender difference of circulating ghrelin and leptin concentrations in chronic Helicobacter pylori infection. Helicobacter 14, 54-60, 2009.

Cindoruk M, Yetkin I, Deger SM, Karakan T, Kan E, Unal S. Influence of H. pylori on plasma ghrelin in patients without atrophic gastritis. World J Gastroenterol 13, 1595-1598, 2007.

Deng ZH, Chu B, Xu YZ, Zhang B, Jiang LR. Influence of H. pylori infection on Ghrelin levels in children. World J Gastroenterol 18, 5096-5100, 2012.

Du T, Sun X, Yin P, Huo R, Ni C, Yu X. Increasing trends in central obesity among Chinese adults with normal body mass index, 1993-2009. BMC Public Health 13, 327, 2013.

Ericksen RE, Rose S, Westphalen CB, Shibata W, Muthupalani S, Tailor Y, Friedman RA, Han W, Fox JG, Ferrante AW Jr, Wang TC. Obesity accelerates Helicobacter felis-induced gastric carcinogenesis by enhancing immature myeloid cell trafficking and TH17 response. Gut 63, 385-394, 2014.

Fernandez-Real JM, Pickup JC. Innate immunity, insulin resistance and type 2 diabetes. Trends Endocrinol Metab 19, 10-16, 2008.

Fujiwara Y, Higuchi K, Arafa UA, Uchida T, Tominaga K, Watanabe T, Arakawa T. Long-term effect of Helicobacter pylori eradication on quality of life, body mass index, and newly developed diseases in Japanese patients with peptic ulcer disease. Hepatogastroenterology 49, 1298-1302, 2002.

Garrow JS, Webster J. Quetelet's index (W/H2) as a measure of fatness. Int J Obes 9, 147-153, 1985.

Gen R, Demir M, Ataseven H. Effect of Helicobacter pylori eradication on insulin resistance, serum lipids and lowgrade inflammation. South Med J 103, 190-196, 2010.

Gokcel A, Gumurdulu Y, Kayaselcuk F, Serin E, Ozer B, Ozsahin AK, Guvener N. Helicobacter pylori has no effect on plasma ghrelin levels. Eur J Endocrinol 148, 423-442, 2003.

Goodwin CS, Mendall MM, Northfield TC. Helicobacter pylori infection. Lancet 349, 265-269, 1997.

Hassouna R, Zizzari P, Tolle V. The ghrelin/obestatin balance in the physiological and pathological control of growth hormone secretion, body composition and food intake. J Neuroendocrinol 22, 793-804, 2010.

Huda MS, Durham BH, Wong SP, Deepak D, Kerrigan D, McCulloch P, Ranganath L, Pinkney J, Wilding JP. Plasma obestatin levels are lower in obese and post-gastrectomy subjects, but do not change in response to a meal. Int J Obes 32, 129-135, 2008.

Cui H, Lopez M, Rahmouni K. The cellular and molecular bases of leptin and ghrelin resistance in obesity. Nat Rev Endocrinol 13, 338-351, 2017.

Jeffery PL, McGuckin MA, Linden SK. Endocrine impact of Helicobacter pylori: focus on ghrelin and ghrelin oacyltransferase. World J Gastroenterol 17, 1249-1260, 2011.

Khosravi Y, Bunte RM, Chiow KH, Tan TL, Wong WY, Poh QH, Doli Sentosa IM, Seow SW, Amoyo AA, Pettersson S, Loke MF, Vadivelu J. Helicobacter pylori and gut microbiota modulate energy homeostasis prior to inducing histopathological changes in mice. Gut Microbes 7, 48-53, 2016.

Kim TJ, Lee H, Kang M, Kim JE, Choi YH, Min YW Min BH, Lee JH, Son HJ, Rhee PL, Baek SY, Ahn SH, Kim JJ. Helicobacter pylori is associated with dyslipidemia but not with other risk factors of cardiovascular disease. Sci Rep 6, 38015, 2016.

Lee ES1, Yoon YS, Park CY, Kim HS, Um TH, Baik HW, Jang EJ, Lee S, Park HS, Oh SW. Eradication of Helicobacter pylori increases ghrelin mRNA expression in the gastric mucosa. J Korean Med Sci 25, 265-271, 2010.

Matthews DR, Hosker JP, Rudenski AS, Naylor BA, Treacher DF, Turner RC. Homeostasis model assessment: insulin resistance and beta-cell function from fasting plasma glucose and insulin concentrations in man. Diabetologia 28, 412-419, 1985. 
Stec-Michalska K, Malicki S, Michalski B, Peczek L, Wisniewska-Jarosinska M, Nawrot B. Gastric ghrelin in relation to gender, stomach topography and Helicobacter pylori in dyspeptic patients. World J Gastroenterol 15, 5409-5417, 2009.

Nwokolo CU, Freshwater DA, O’Hare P, Randeva HS. Plasma ghrelin following cure of Helicobacter pylori. Gut 52, 637-640, 2003.

Osawa H, Nakazato M, Date Y, Kita H, Ohnishi H, Ueno H, Shiiya T, Satoh K, Ishino Y, Sugano K. Impaired production of gastric ghrelin in chronic gastritis associated with Helicobacter pylori. J Clin Endocrinol Metab 90, 10-16, 2005.

Osawa H. Ghrelin and Helicobacter pylori infection. World J Gastroenterol 14, 6327-6333, 2008.

Quatrini M, Boarino V, Ghidoni A, Baldassarri AR, Bianchi PA, Bardella MT. Helicobacter pylori prevalence in patients with diabetes and its relationship to dyspeptic symptoms. J Clin Gastroenterol 32, 215-217, 2001.

Satoh H, Saijo Y, Yoshioka E, Tsutsui H. Helicobacter Pylori infection is a significant risk for modified lipid profile in Japanese male subjects. J Atheroscler Thromb 17, 1041-1048, 2010.

Sotiropoulos A, Gikas A, Skourtis S, Merkouris P, Pentzeridis P, Polydorou A, Pappas S. Seropositivity to Chlamydia pneumoniae or Helicobacter pylori and coronary artery disease. Int J Cardiol 109, 420-421, 2006.

Wallace TM, Levy JC, Matthews DR. Use and abuse of HOMA modeling. Diabetes Care 27, 1487-1495, 2004.

Ulasoglu C, Isbilen B, Doganay L, Ozen F. Effect of Helicobacter pylori eradication on serum ghrelin and obestatin levels. World J Gastroenterol 19, 2388-2394, 2013.

Yildiz B, Suchard M, Wong M, McCann S, Licinio J. Alterations in the dynamics of circulating ghrelin, adiponectin, and leptin in human obesity. Proc Natl Acad Sci USA 101, 10434-10439, 2004.

Zhang JV, Ren PG, Avsian-Kretchmer O, Luo CW, Rauch R, Klein C, Hsueh AJ. Obestatin, a peptide encoded by the ghrelin gene, opposes ghrelin's effects on food intake. Science 310, 996-999, 2005.

Zhang Y, Du T, Chen X, Yu X, Tu L, Zhang C. Association between Helicobacter pylori infection and overweight or obesity in a Chinese population. J Infect Dev Ctries 9, 945-953, 2015. 